\title{
The Possibility of Using Waste PET Plastic Strip to Enhance the Flexural Capacity of Concrete Beams
}

Wrya A. Abdullah*, Hemn Unis Ahmed*, Younis M. ALSHKANE*, Darko B. Rahman**, Ashkan O. Ali** and Shko S. Abubakr**

*College of Engineering, University of Sulaimani, Iraq

**Civil Engineer, Concrete Laboratory, College of Engineering, University of Sulaimani, Iraq *Email: wrya.faraj@univsul.edu.iq; Corresponding Author.

\begin{abstract}
The most widely used material after water is the concrete composite. However, it is commonly accepted that concrete is weak in tension compared to its compression, therefore, conventionally, it is usually reinforced with steel rebars. Recently, reusing of waste plastic materials has become a norm among researchers whom used it in different forms in improving some mechanical properties of the concrete such as impact and tensile strength. However, using PET plastic strips as a replacement of main steel rebars is a novel idea. Therefore, in this study the experimental laboratory work is conducted to investigate the possibility of using waste plastic strips as a replacement of the main reinforcement steel bars to promote the flexural capacity of concrete beams at 28 days. For this purpose, a total number of 10 beams were casted with dimensions of $(200 \mathrm{~mm} \times 200 \mathrm{~mm} \times 1200 \mathrm{~mm})$ to investigate the effects of using waste plastic strips in enhancing the bending capacity of the beams. The results showed that the incorporation of the plastic strips can improve the load carrying capacity and toughness of the concrete beams compared to unreinforced concrete beams.
\end{abstract}

Key words: Concrete; recycling plastics; flexural Strength; Deflection. 


\section{INTRODUCTION}

One of the significant innovations of the twentieth century was plastics and their usage has become prevalent all over the world. Nowadays, the use of plastic has significantly increased, which leads to accumulation of a considerable amount of waste plastics in the environment all over the world (Saikia and De Brito, 2012). Over the last two decades, waste plastics were accounted for causing a big issue to the environment they are measured as one of the extreme risky sources of environmental pollution (Ismail and Al-Hashmi, 2008) (Al-Salem et. al., 2009) (Guerrero et. Al., 2013) (Iucolano et. al., 2013) (Wu et. al., 2013) (Liguori et. al., 2014).

Globally, plastic manufacturing has been skyrocketed. For instance, only in 2018, about 359 million tons of plastics were produced where $51 \%$ of these plastics were made in Asia and $17 \%$ were made in Europe (Europe, 2019). EU28+NO/CH in 2018, illustrated the remediation of waste plastics which is presented in Figure1. In the same year, around $32.5 \%$ of post-consumer plastics was mechanically recycled, $42.6 \%$ was recovered for energy, and the rest $24.9 \%$ was landfilled among the total plastic wastes (Europe, 2019).

Plastics have a bulky nature and degrade very slowly, so they cause serious challenges when they are land-filled, because they may restrict the underground water movement, and also cause obstacles to tree roots. It should also be known that the lead and cadmium are ingredients of waste plastics which contain a variety of toxic materials that may pollute earth soils and water when they mix with rainwater.

Therefore, to tackle the negative effects of post-consumer plastics on the environment, recycling and reusing them are measured as one of the best solutions. In recent years many studies have been conducted to reuse of waste plastics in a mortar and concretes in different forms such as an alternative to natural sands (Aslani, 2016) (Aslani, et. al., 2018) (Bušić, et. al., 2018) (Faraj, et. al., 2019) (Thorneycroft, et. al., 2018) (Kohistani and Singh, 2018) (Verdolotti et al., 2014), or as fiber to reinforce mortar and concretes (Boiny et. al., 2016) (Alshkane et. al., 2017) 
(Mohammed and Rahim, 2020). The researchers have reused different types of post-consumer plastics, for instance, polypropylene(pp) (Yang et. al., 2015), polyvinyl chloride (PVC) pipes (Kou et. al., 2009), expanded polystyrene foam (EPS) (Kan and Demirboğa, 2009), high density polyethylene (HDPE) (Naik et. al., 1996), thermosetting plastics (Panyakapo and Panyakapo, 2008), polycarbonate (Hannawi et. al., 2010), polyurethane foam (Fraj et. al., 2010) (Mounanga et. al., 2008), glass reinforced plastics (GRP) (Asokan et. al., 2010), and polyethylene terephthalate (PET) (Harini and Ramana, 2015), (Boiny et. al., 2016), (Alshkane et. al., 2017) and (Mohammed and Rahim, 2020).

PET is the most used thermoplastic polyester and it has a good mechanical and dimensional stability performance under variable loads. It also has a good chemical and gas barrier properties (Jabarin, 1996).

On the global level, the most frequently used construction material is the concrete, which is made by mixing sand, gravel, cement, water, and sometimes admixtures. This important construction material has a weak point which is a low tensile strength compared to its compressive strength. Therefore, steel reinforcement has been used to improve the tensile behavior of concrete elements (Neville, 1995). In addition, many research studies have been conducted on the structural concrete level to study the structural behavior of concrete which contains a variety form of post-consumer plastics (Dai et. al., 2012), (Mahdi et. al., 2013), (Marthong and Marthong, 2016), (Zhang et. al., 2016), (Mohammed, 2017), and (Kim et. al., 2010). However, using PET strips as replacement of main steel rebar is very rare.

This study is conducted to show the possibility of using waste plastic strips as the main bars to reinforce normal concrete beams compared to plain and steel reinforced concrete beams. The source of waste plastic strips used are the leftovers of packaging industry as they were used in fastening different forms of materials such as brick and blocks. Nine, six and three strips of this 
waste plastic strips are used as main bars reinforcement in the concrete beams and then tested at 28 days.

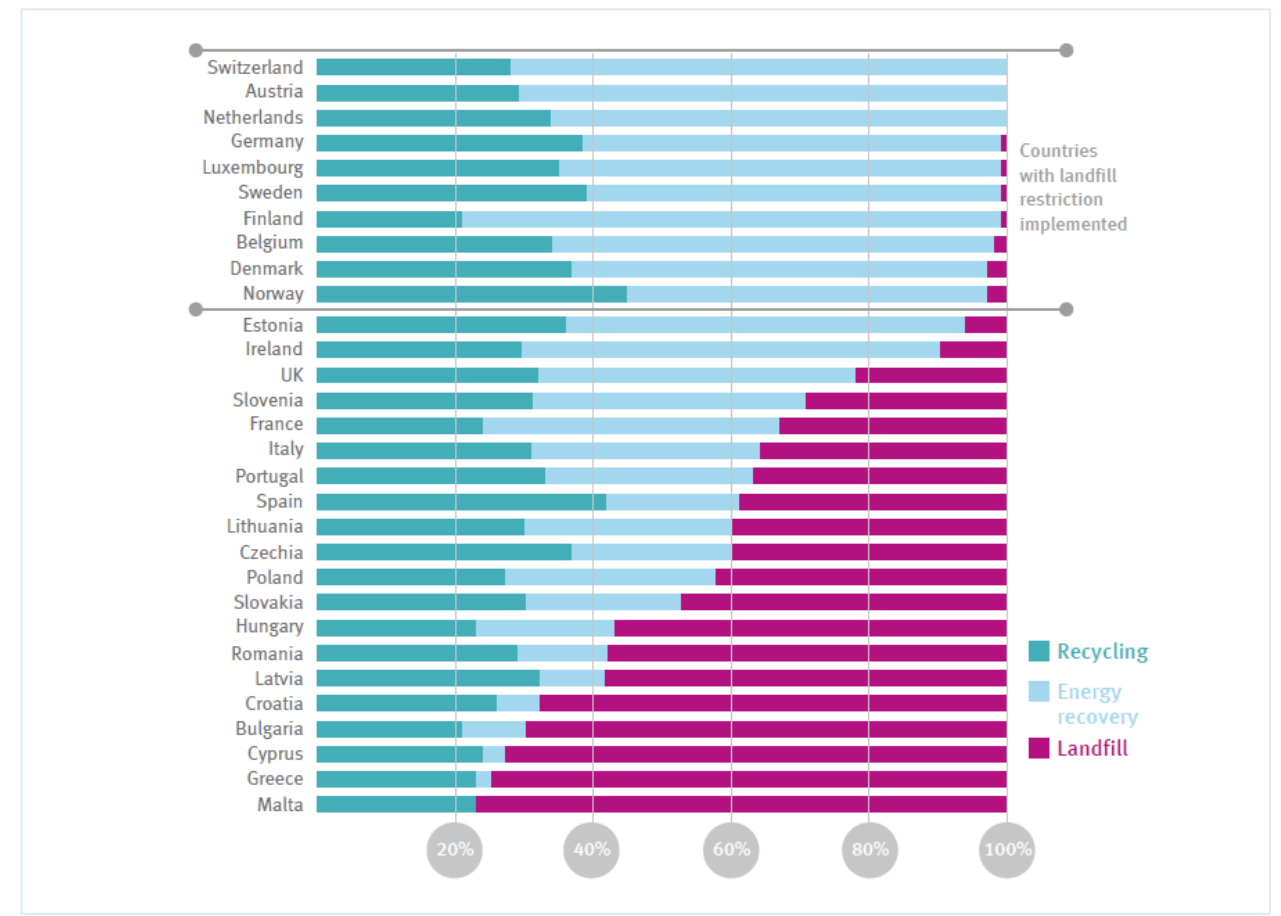

Figure 1 Plastic post-consumer waste rates of recycling, energy recovery and landfill per country in 2018 by EU28+NO/CH (Europe, 2019)

\section{SIGNIFICANCE OF THIS STUDY}

Conventionally, steel reinforcement is commonly used to reinforce concrete elements, but one of the challenges of this century is to find out an alternative material to replace steel bars inside the concrete elements. Another issue related to this century is the possibility of reusing of waste materials to protect our environment from pollution. Therefore, this research aims to show the possibility of using waste plastic strips to reinforce normal concrete beams. It can be counted as an attempt to contribute in tackling the above related issues.

\section{MATERIALS AND METHODOLOGY}

The materials are available in the local areas of (Sulaimaniyah City, Qalachwalan, and Darbandikhan). All the materials are tested and then mixed to prepare the samples.

\section{MATERIALS}


The following materials are used in this study:

\section{CEMENT}

Ordinary Portland Cement is used which is commercially available in Tasluja Cement Factory in Sulaimaniyah, Iraq. The compressive strength of the cement was tested based on ASTM C10916 after 28 days which was $26.8 \mathrm{MPa}$, and if they compared with ASTM C150- 17 and ASTM C778-17, it can be found that it is more than the minimum value required by the code.

\section{COARSE AGGREGATE}

The maximum size of the aggregate is selected to be $25 \mathrm{~mm}$ and a crushed stone type is used for the sake of the designing the mixes which is available in Qalachwalan quarry after testing some samples brought in Darbandikhan and Qalachwalan. Figure 2 shows the sieve analysis results of the coarse aggregate based on the procedures describes in ASTM C136-14, and then compared to the ranges set by ASTM C33-16. The specific gravity of the coarse aggregate was 2.69 according to the procedures indicated in ASTM C127-15.

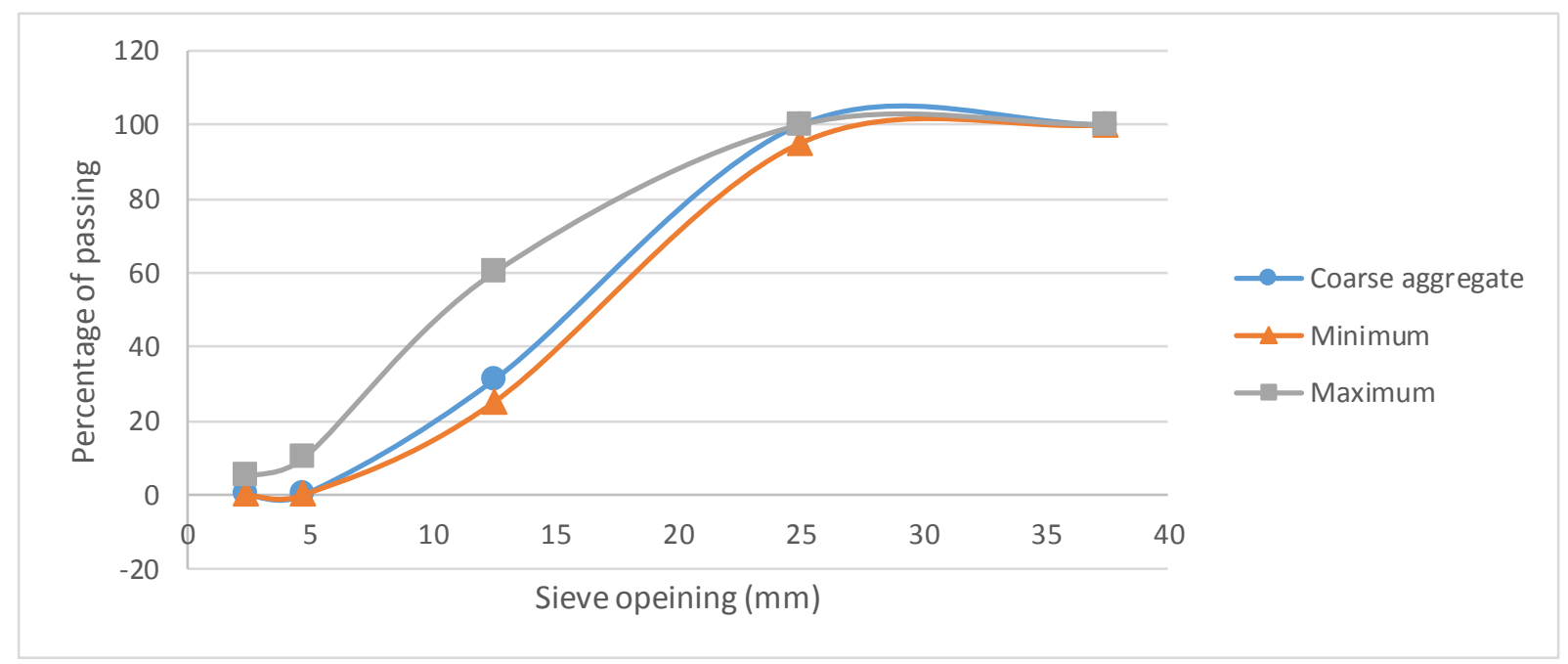

Figure 2 Sieve analysis of the coarse aggregate

\section{FINE AGGREGATE}

The fine aggregate had the maximum size of $4.75 \mathrm{~mm}$ which its source was Darbandikhan quarry. Figure 3 shows sieve analysis of the sample compared with the ranges provided by ASTM C33-16. The specific gravity of the sand was 2.62 based on the procedures that describes 
in ASTM C128-15.

\section{PLASTIC STRIPS}

Plastic strips were $12 \mathrm{~mm}$ wide and $0.8 \mathrm{~mm}$ thick and green in color. They were reused from the construction sites where initially used in package industry. The elongation of them varied between $10-15 \%$ with the breaking strength variation of $40-50 \mathrm{~kg} / \mathrm{mm}^{2}$.

\section{SPECIMENS}

The total number of 10 beams were cast. Those ten beams are distributed to represent some variables in the number of the plastic strips used in each beam. For each variable two beams were cast. Based on the design of a load of $50 \mathrm{kN}$, the dimensions of the beams are selected to have a cross section of $200 \mathrm{~mm}$ x $200 \mathrm{~mm}$ and the length of $1200 \mathrm{~mm}$ with a clear span of 1000 $\mathrm{mm}$ between the supports. Figure 4 shows the beam profile with its designing load. The two control beams had no reinforcement and they are called "plain beams" hereafter. The beams are considered as simply supported beams.

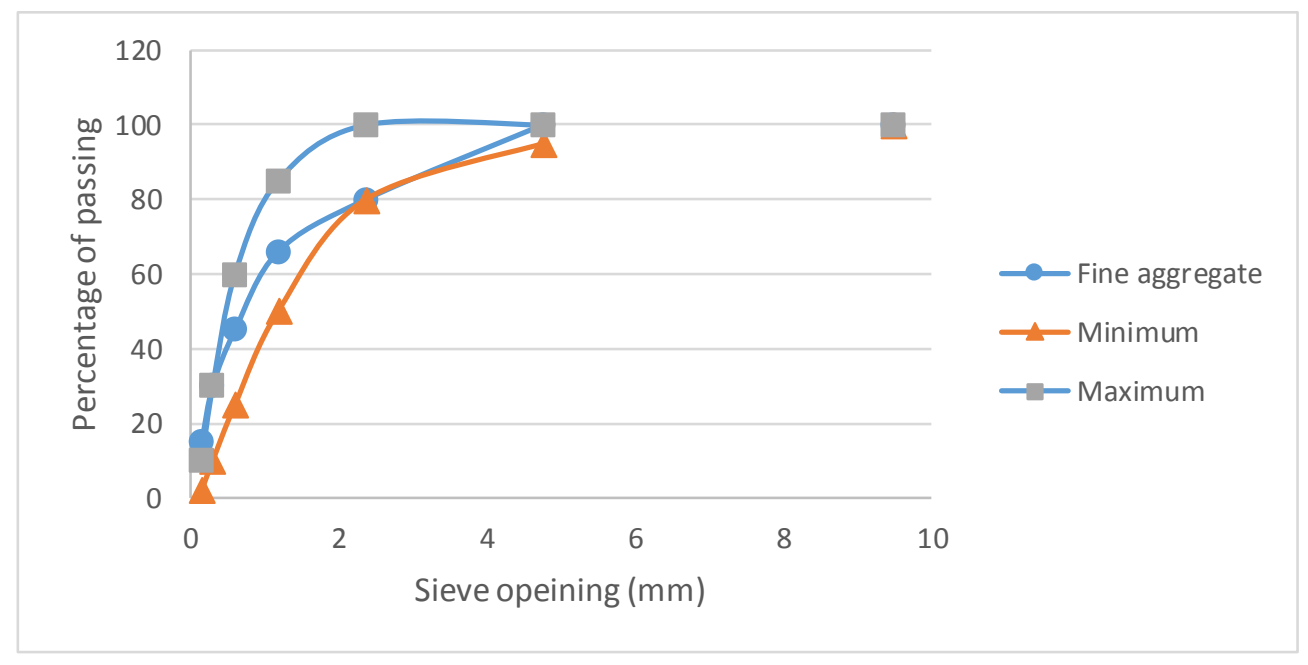

Figure 3 Sieve analysis of the fine aggregate

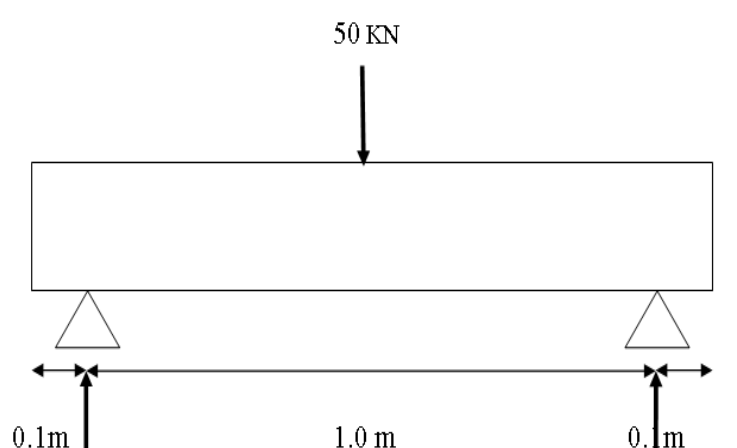


Figure 4. The beam configuration with its design load and reactions including the self-weight of the beam

After the designing process, it was found that 3 reinforce rebars with $10 \mathrm{~mm}$ of diameters are required to resist the applied load of $50 \mathrm{kN}$. However, the target was to use plastic strips instead of reinforce bars. Therefore, three sets of beams were cast each with having a different number of plastic strips as replacements for the number of the steel rebars regardless of the difference in their areas. The number of bars is replaced with multiplying the numbers by two each time. Therefore, two beams were casted to have 3 strips of plastic at the bottom as a replacement for the three reinforcement steel bars. More, two beams were cast to have 6 strips of plastic at the bottom of the beam arranged in three strips with two layers on top of each other. Finally, two beams were cast with 9 strips of plastic at the bottom of the beam arranged in three rows with three layers of plastic strips on top of each other. To compare the effectiveness of the strips with the conventional reinforced steel beams as an additional step, two beams were cast with 3 steel bars in their tension zone.

To ensure the flexural failure of the beams, all the beams, apart from the plain beams, were supplied with traverse reinforcement of $10 \mathrm{~mm}$ with a spacing of $200 \mathrm{~mm}$. Also, to hold up the stirrups, except for the plain beams, all the other beams had two $10 \mathrm{~mm}$ steel bars on top. The plastic strips were fastened to the stirrups in the same manner as normal reinforce bars. Figure 5 shows an example of the molds with the strips at the bottom of the beams. 


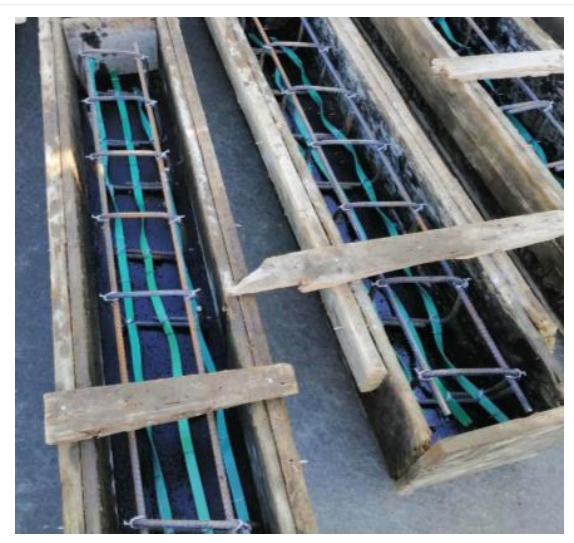

Figure 5 Beam molds with plastic strips.

MIXING

All the beams were cast from the same mix and the same day. The beams were taken out from their molds after two days of their casting and transferred to the "concrete laboratory" in College of Engineering in the Sulaimani University. The average compressive strength of the concrete was $21 \mathrm{MPa}$ after 28 days. Figure 6 shows the labelled samples just after transferring them to the university.

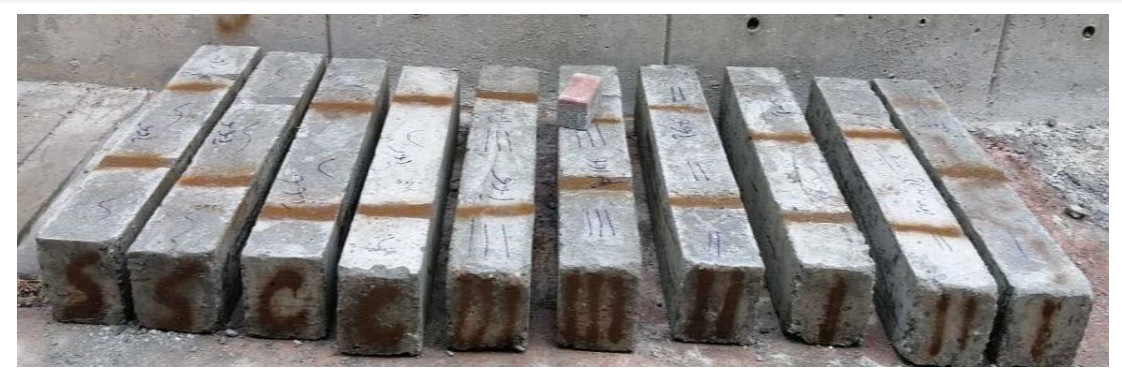

Figure 6 Label of the beams after transferring them to the lab premises.

\section{TESTING THE SPECIMENS}

The specimens were tested in accordance to ASTM C293 using flexural testing machine from Control company available in the "concrete laboratory" in College of Engineering of Sulaimani University. The samples were loaded until failure with the rate of $1 \mathrm{~N} / \mathrm{mm}^{2} /$ minute. Figure 7 shows a specimen under the loading machine. A dial gauge, shown in Figure 8, was used to measure the deflection of the beams. The test is performed using three-point flexural testing. The 
clear span of the beam was $1000 \mathrm{~mm}$ as $100 \mathrm{~mm}$ is left for the supports to rest on the supports form both ends of the beam. Also, and the load is applied from the center of the beam, therefore, the distance from the edge of the load to the supports is $500 \mathrm{~mm}$.

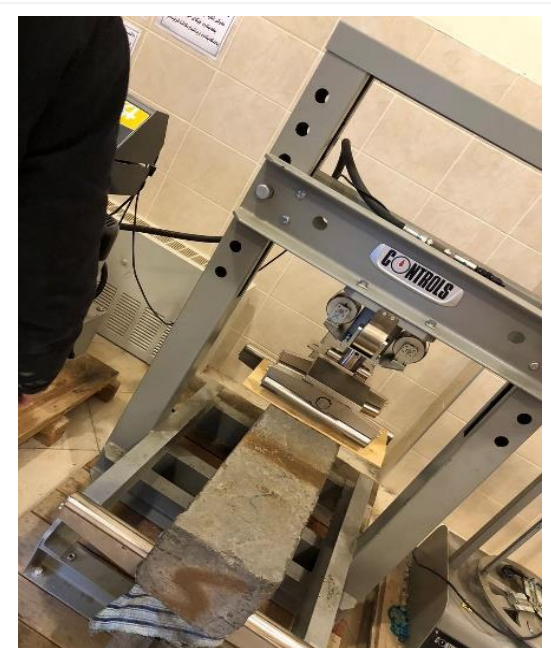

Figure 7 Concrete beam under the flexural testing machine

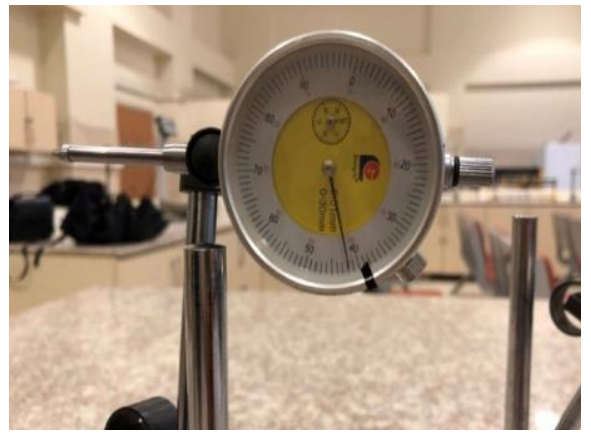

Figure 8 Dial gauge used in measuring the mid span deflection

RESULTS AND DISCUSSION

After testing all the beams for bending, it was found out that the average ultimate load that can be carried by the plain beams was only $8.8 \mathrm{kN}$ with the average deflection of $2 \mathrm{~mm}$, see Figure 9. However, this ultimate load has increased to $28.18 \mathrm{kN}$ when only three plastic strips were used in the tension zone. Additionally, the defection capacity of the beam has increased by $190 \%$ to reach approximately $6 \mathrm{~mm}$. These numbers were elevated when 6 strips of plastic were used where the failure load reached $31.1 \mathrm{kN}$ which represents $253 \%$ of increase which is due to having a plastic strip which have fairly good tensile strength. Also, the deflection of the beams has increased to $8.62 \mathrm{~mm}$ which counts for $330 \%$ of increase in the deflection. Finally, the best case 
of using strips has happened when 9 strips were used in the tension zone where the ultimate load was $36 \mathrm{kN}$ which means $310 \%$ increase compared to the control samples. Additionally, the maximum deflection of the beam was $12.32 \mathrm{~mm}$ which is $516 \%$.

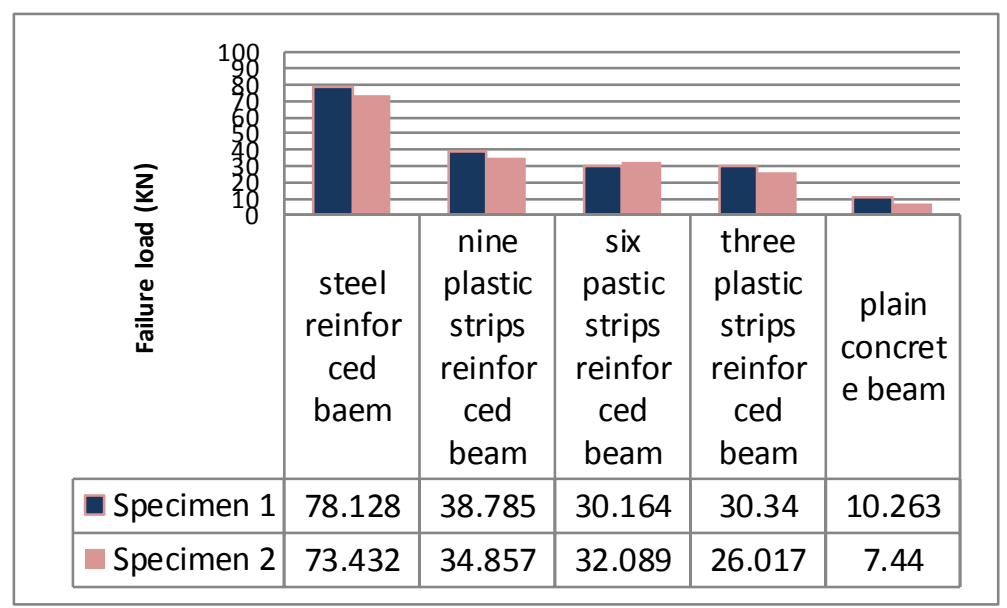

Figure 9 Ultimate load of the sample beams.

To comprehend the effectiveness of using plastic strips as a replacement of steel rebars, the beams with steel rebars showed superiority as their tensile strengths are more than that of the plastic strips. The ultimate load carried by the steel reinforced beams was $75 \mathrm{kN}$ which was nearly twice of the capacity of the beams with 9 strips and it is $752 \%$ increase if compared with the control samples without any reinforcement.

The deflection of the steel reinforced beams was less than that of the plastic reinforced beams despite of the difference in their cross-sectional areas. From Figure 10, it can be seen that using plastic strips lead to a ductile failure mode while it is a brittle mode when no reinforcement is provided in the tension zones of the beams. Moreover, it can be noticed that using steel bars in reinforcing beams can enhance the strength of the sections while the ductility can be improved when plastic strips are used. This will be particularly beneficial when a ductile structure is needed or some parts of the buildings need to be ductile as in the case of designing buildings for earthquake loads. Also, it would be a significant replacement for the steel bars where only the minimum reinforcement is required for controlling shrinkage and temperature. Therefore, this 
type of plastic strip can be used in the zones where secondary or minimum rebars are required. Additionally, using plastic strips for the foundation can improve the tensile strength of it without providing concrete cover which is needed when reinforced bars provided due to fear of corrosion. If only deflection is to be compared, then the beam with 9 strips of PET has deflected $35 \%$ more than that of the ultimate deflection of the steel reinforced beam. If their deflection is to be compared for the same load, it can be seen that they have similar deflections until the load application of $30 \mathrm{kN}$. However, at its ultimate load carrying capacity of $40 \mathrm{kN}$, the deflection of the beams with 9 strips of plastic was three times of that of the steel reinforced beam.

Furthermore, it can be noticed that the failure mode was brittle when no reinforcement was provided in the beam, however, the mode has changed to be more ductile after providing PET or steel in tensioning zone. Finally, it can be observed that the ductility of the beams increases with increasing the number of plastic strips in the tensioning zone as the beam with 9 strips shows better ductility that the beam with only 3 strips.

It worth mentioning that there is a sudden increase in deflection of the beams reinforced with plastic strips. This can be seen after applying approximately $25 \mathrm{kN}$ on the beams. The reason for that might be debonding between the concrete paste and the plastic strips. For this reason, it is a recommendation for future work to find the bond between the concrete and the plastic strips.

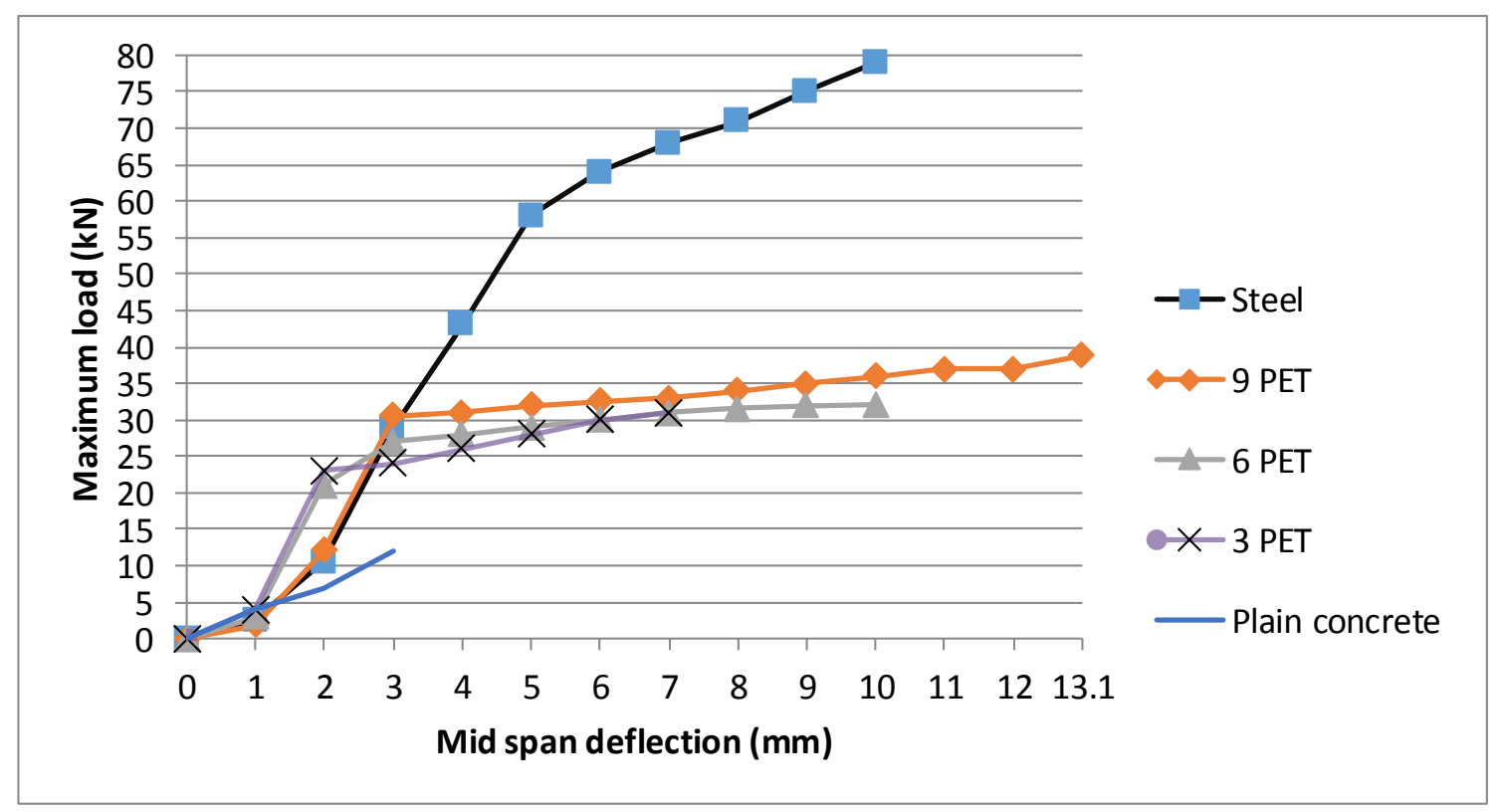


Figure 10 Load- deflection diagram of the beams.

\section{CONCLUTIONS}

Based on the results of this study it can be concluded that:

1- Waste plastic strips used in package industry can be used successfully in the tension zones of concrete beams to partially replace the steel bars especially where the tensile strength required is not large enough and only minimum reinforcement should be provided for shrinkage and temperature.

2- The load carrying capacity of the plain concrete beam can be enhanced by $225 \%$, if only 3 plastic strips are provided, and by $280 \%$ if 9 strips of PET are provided in the tensile zone of the beams.

3- The ultimate deflection of a plain beam can increase by $190 \%$, if only 3 strips of PET are provided, and by more than $500 \%$ if 9 strips of PET are provided in the tensioning zone of the beams.

4- The usage of PET strips can be a suitable way in reusing them inside the concrete. Even though, more research work is needed to verify the other aspects of using plastic strips such as bonding concerns.

5- The ductility of the beams increases with an increase in the number of strips as the beams with 9 PET strips in their tension zones had greater deflection capacity compared to those beams with only 3 plastic strips in their tensioning zone.

6- When compared to the usage of steel, PET may partially replace the steel bars in tensioning zone if replaced with equivalent areas not with equivalent numbers. In this research the 
comparison is performed to understand the efficiency of the PET with respect to steel reinforcement which is found that the load carrying capacity of the PET reinforced beams with 9 strips of PET can reach nearly half $(36.82 \mathrm{kN})$ of that of the beams reinforced with 3 bars of steel $(76.78 \mathrm{kN})$.

\section{REFERENCES}

Al-Salem, S. M., Lettieri, P., \& Baeyens, J. (2009). Recycling and recovery routes of plastic solid waste (PSW): A review. Waste management, 29(10), 2625-2643.

Alshkane, Y. M., Rafiq, S. K., Boiny, H. U. (2017). Correlation between Destructive and Non-Destructive Tests on the Mechanical Properties of Different Cement Mortar Mixtures incorporating Polyethylene Terephthalate Fibers. Sulaimani Journal for Engineering Sciences, 4 (5).

Aslani, F. (2016). Mechanical properties of waste tire rubber concrete. Journal of Materials in CivilEngineering, 28(3), 04015152.

Aslani, F., Ma, G., Wan, D. L. Y., \& Muselin, G. (2018). Development of highperformance self-compacting concrete using waste recycled concrete aggregates and rubber granules. Journal of Cleaner Production, 182, 553-566.

Asokan, P., Osmani, M., \& Price, A. D. (2010). Improvement of the mechanical properties of glass fibre reinforced plastic waste powder filled concrete. Construction and Building Materials, 24(4), 448-460.

Boiny, H. U., Alshkane, Y. M., \& Rafiq, S. K. (2016, October). Mechanical properties of cement mortar by using polyethylene terephthalate fibers. In 5th National and 1st International Conference on Modern Materials and Structures in Civil Engineering, Iran 
(Islamic Republic of Iran).

Bušić, R., Miličević, I., Šipoš, T. K., \& Strukar, K. (2018). Recycled rubber as an aggregate replacement in self-compacting concrete-Literature overview. Materials, 11(9), 1729.

Dai, J. G., Lam, L., \& Ueda, T. (2012). Seismic retrofit of square RC columns with polyethylene terephthalate (PET) fibre reinforced polymer composites. Construction and Building Materials, 27(1), 206-217.

Europe, P. (2019). An analysis of European plastics production, demand and waste data. Plastics-thefacts.

Faraj, R. H., Sherwani, A. F. H., \& Daraei, A. (2019). Mechanical, fracture and durability properties of self-compacting high strength concrete containing recycled polypropylene plastic particles. Journal Of Building Engineering, 25, 100808.

Fraj, A. B., Kismi, M., \& Mounanga, P. (2010). Valorization of coarse rigid polyurethane foam waste in lightweight aggregate concrete. Construction and Building Materials, 24(6), 1069-1077.

Guerrero, L. A., Maas, G., \& Hogland, W. (2013). Solid waste management challenges for cities in developing countries. Waste management, 33(1), 220-232.

Hannawi, K., Kamali-Bernard, S., \& Prince, W. (2010). Physical and mechanical properties of mortars containing PET and PC waste aggregates. Waste management, 30(11), $2312-2320$

Harini, B., and Ramana, K. V., (2015). Use of Recycled Plastic Waste as Partial Replacement for Fine Aggregate in Concrete. IJIRSET, vol. 4, pp. 8596.

Ismail, Z. Z., \& Al-Hashmi, E. A. (2008). Use of waste plastic in concrete mixture as aggregate replacement. Waste management, 28(11), 2041-2047.

Iucolano, F., Liguori, B., Caputo, D., Colangelo, F., \& Cioffi, R. (2013). Recycled plastic 
aggregate in mortars composition: Effect on physical and mechanical properties. Materials \& Design (1980-2015), 52, 916-922.

Jabarin, S. A. (1996). Polyethylene terephthalate chemistry and preparation. Polymeric Materials Encyclopedia, 4, 6079-6085.

Kan, A., \& Demirboğa, R. (2009). A novel material for lightweight concrete production. Cement and Concrete Composites, 31(7), 489-495.

Kim, S. B., Yi, N. H., Kim, H. Y., Kim, J. H. J., \& Song, Y. C. (2010). Material and structural performance evaluation of recycled PET fiber reinforced concrete. Cement and concrete composites, 32(3), 232-240.

Kohistani, A. S., \& Singh, K. (2018). An Experimental Investigation by Utilizing Plastic Waste and Alccofine in Self-Compacting Concrete. Indian Journal of Science and Technology, 11, 26.

Kou, S. C., Lee, G., Poon, C. S., \& Lai, W. L. (2009). Properties of lightweight aggregate concrete prepared with PVC granules derived from scraped PVC pipes. Waste Management, 29(2), 621-628.

Liguori, B., Iucolano, F., Capasso, I., Lavorgna, M., \& Verdolotti, L. (2014). The effect of recycled plastic aggregate on chemico-physical and functional properties of composite mortars. Materials \& Design, 57, 578-584.

Mahdi, F., Abbas, H., \& Khan, A. A. (2013). Flexural, shear and bond strength of polymer concrete utilizing recycled resin obtained from post-consumer PET bottles. Construction and Building Materials, 44, 798-811.

Marthong, C., \& Marthong, S. (2016, February). An experimental study on the effect of PET fibers on the behavior of exterior RC beam-column connection subjected to reversed cyclic loading. In Structures (Vol. 5, pp. 175-185). Elsevier.

Mohammed, A. A. (2017). Flexural behavior and analysis of reinforced concrete beams 
made of recycled PET waste concrete. Construction and Building Materials, 155, 593-604.

Mohammed, A. A., \& Rahim, A. A. F. (2020). Experimental behavior and analysis of high strength concrete beams reinforced with PET waste fiber. Construction and Building Materials, 244, 118350.

Mounanga, P., Gbongbon, W., Poullain, P., \& Turcry, P. (2008). Proportioning and characterization of lightweight concrete mixtures made with rigid polyurethane foam wastes. Cement and Concrete Composites, 30(9), 806-814.

Naik, T. R., Singh, S. S., Huber, C. O., \& Brodersen, B. S. (1996). Use of post-consumer

waste plastics in cement-based composites. Cement and concrete research, 26(10), 14891492.

Neville, A. M. (1995). Properties of concrete (Vol. 4). London: Longman.

Panyakapo, P., \& Panyakapo, M. (2008). Reuse of thermosetting plastic waste for lightweight concrete. Waste management, 28(9), 1581-1588.

Saikia, N., \& De Brito, J. (2012). Use of plastic waste as aggregate in cement mortar and concrete preparation: A review. Construction and Building Materials, 34, 385-401.

Thorneycroft, J., Orr, J., Savoikar, P., \& Ball, R. J. (2018). Performance of structural concrete with recycled plastic waste as a partial replacement for sand. Construction and Building Materials, 161, 63-69.

Verdolotti, L., Iucolano, F., Capasso, I., Lavorgna, M., Iannace, S., \& Liguori, B. (2014). Recycling and recovery of PE- PP- PET- based fiber polymeric wastes as aggregate replacement in lightweight mortar: Evaluation of environmental friendly application. Environmental Progress \& Sustainable Energy, 33(4), 1445-1451.

Wu, G., Li, J., \& Xu, Z. (2013). Triboelectrostatic separation for granular plastic waste recycling: A review. Waste management, 33(3), 585-597. 
Yang, S., Yue, X., Liu, X., \& Tong, Y. (2015). Properties of self-compacting lightweight concrete containing recycled plastic particles. Construction and Building Materials, 84, 444453.

Zhang, D., Zhao, Y., Jin, W., \& Ueda, T. (2016). Effect of PET wrapping on shear performance of corroded reinforced concrete columns. 